\title{
Valuation of Mortgage Servicing Rights with Foreclosure Delay and Forbearance Allowed
}

\author{
CHE-CHUN LIN* \\ Department of Quantitative Finance, National Tsing Hua University, Hsin Chu, Taiwan 30013, \\ Tel: (886) 3-5742419, Fax (886) 3-5715403 \\ E-mail: chclin@mx.nthu.edu.tw \\ TING-HENG CHU \\ LARRY J. PRATHER \\ Department of Economics, Finance, and Urban Studies, East Tennessee State University, Box 70686, \\ Johnson City, TN 37614 \\ E-mail: chut@etsu.edu \\ E-mail: prather@etsu.edu
}

\begin{abstract}
We develop a bivariate binomial model to price Mortgage Servicing Rights (MSRs). Our model is an improvement over previous MSR pricing models by explicitly incorporating the realistic assumptions that there are additional costs involved in servicing delinquent loans. In addition to the Hilliard et al. mortgagepricing tree, we extend additional sub-branches to model the borrower's decision of prepayment, cure, and foreclosure after a loan becomes delinquent. We then investigate how the value of the Mortgage Servicing Right varies with interest rate volatility, house price volatility, delinquency options, deficiency judgments, default penalties, forbearance periods, and speed of adjustments factors.
\end{abstract}

Key words: mortgage servicing right, prepayment, default

JEL Classification: C15, G21

\section{Introduction}

After financial institutions originate mortgages, they often sell them to conduits such as Fannie Mae and Freddie Mac. Once these conduits buy the mortgages from the originators, these two government-sponsored entities (GSEs) then securitize the mortgages, which creates mortgage-backed securities. A key activity required for a successful mortgage securitization is mortgage servicing.

A Mortgage Servicing Right (MSR) is a contract between the buyers of a residential mortgage pool and the mortgage servicer. Under this servicing contract, the servicer provides the link between the mortgage borrowers and the mortgage owners. The functions that the mortgage servicer provides include collecting payments from the borrowers and passing the appropriate principal and interest payments through to the investors in the secondary market. The servicer also keeps the records of all of the mortgage transactions and manages the borrowers' escrow accounts. Moreover, servicers also send a notice of 
delinquency, default, and in some cases initiate foreclosure processes on defaulted loans. Customarily, the servicer collects a monthly fee in return for the services provided. In addition, the servicer is entitled to earn certain other fees such as float income and late payment fees. ${ }^{1}$ Servicers incur significant expenses associated with servicing that include administrative costs as well as delinquency and foreclosure costs. When servicing income exceeds the servicing expense, the servicing right has created value. Therefore, the value of the MSR is essentially the present value of net cash flows generated from servicing operations.

Fannie Mae and Freddie Mac buy mortgage loans from the originators on either a servicing-retained or a servicing-released basis. If loans are purchased on a servicingretained basis, the originator also acts as the servicer. However, a third party may be appointed to serve as the servicer if loans are purchased on a servicing-released basis. Regardless of the servicing structure, it is imperative to evaluate the value of the MSR. In principle, the MSR value represents the maximum price that a third party should be willing to pay for receiving the servicing rights or the maximum origination costs that the originators should be willing to spend to retain the servicing and still make fewer economic profit.

To value the MSR, we develop an options-based pricing model in which we model interest rates and house prices by utilizing a bivariate binomial lattice subject to boundary conditions. $^{2}$ Using the MSR pricing model developed, we initially measure the value of the MSR in the case where default is synonymous with foreclosure. We then calculate the value for the case in which the default option is separated into two components: delinquency and foreclosure. Consequently, the contribution of our model is to introduce the term "foreclosure delay" into the MSR valuation process in a manner consistent with industry common practice.

The organization of this paper is as follows. The next section reviews the MSR literature and the third section presents the methodology used in our paper. The fourth section reports our results. The final section presents our conclusions and some policy suggestions for the mortgage servicing industry.

\section{Literature review}

Relative to the general mortgage literature the literature devoted to MSRs is sparse. McConnell (1976) develop a static cash flow model, which became one of the first MSR models. The difficulty with using a static cash flow model for MSR valuation is that it ignores the stochastic nature of interest rates and the path-dependent nature of mortgage and MSR cash flows. Van Drunen and McConnell (1988) improve upon McConnell's model by developing a two-state continuous-time model that allows for stochastic real interest rates and stochastic inflation rates. Their model explicitly values the borrower's prepayment option but it ignores default and the effect that both default and delinquency can have on MSR valuation.

Brown et al. (1992) use an Option Adjusted Spread model to price MSRs and to evaluate the effect that prepayments have on MSR values. Their results show that MSRs are similar to Interest-Only (IO) mortgage strips in many ways and that MSRs are extremely sensitive to prepayments. Lin and Ho (2005) employ an Option Adjusted Spread model 
together with the Office of Thrift Supervision prepayment model to price fixed-rate and adjustable-rate MSRs. Their results show that the value of an adjustable-rate MSR is relatively insensitive to prepayments, unlike that of a fixed-rate MSR. Angbazo et al. (1998) price the prepayment float and provide business strategy implications to servicers. Aldrich, Greenberg and Payner (2001) present a comprehensive model of MSR cash flows. They note that the holder of the MSR can receive cash from a number of sources including float, late payment charges, and ancillary charges. Most important, they recognize that the costs of servicing vary depending upon the delinquency and early payment patterns of the borrowers.

The papers cited above are mainly concerned with MSR valuation from a pure capital market perspective in which they focus on interest rate risk and treat prepayment, delinquency, and default as exogenous events. In essence, this forces the researchers to treat MSRs as an oddly formed IO instrument. In fact, Aldrich, Greenberg, and Payner (2001) explicitly note that they "treat mortgage servicing as just another structured IO."

The difficulty with such an approach is that the MSR is not just a financial instrument. Unlike a bond or stock, the holder of the MSR must work to receive cash flows. Thus, a servicer that can do the work more efficiently and with lower costs should be able to extract higher returns than a less efficient servicer. Furthermore, an IO-style model may miss the fact that there may be incentive conflicts between the mortgage servicer and the mortgage guarantor or investor. The model we develop below explicitly incorporates the impact of the costs associated with servicing.

\section{Model development}

We utilize a bivariate-binomial model to evaluate MSRs. Our model is based upon the Hilliard, Kau and Slawson (1998) mortgage pricing model with the extensions of Ambrose and Buttimer (2000) who introduced a more detailed specification of the default process on mortgage pricing decision. More important, our servicing valuation model is the extensions of Buttimer and Lin (2005) and we further treat default and delinquency as endogenous events. This allows us to study explicitly the costs associated with servicing and allows us to examine the actions that a servicer may take to maximize the value of the MSR of a delinquent loan.

The model contains two sources of uncertainty, interest rates and house prices. Interest rates $(r)$ are assumed to follow the Cox, Ingersoll and Ross (1985) process:

$$
d r=\gamma(\theta-r) d t+\sigma_{r} \sqrt{r} d z_{r},
$$

where $\theta$ is the steady-state mean rate, $\gamma$ is the speed of adjustment, $\sigma_{r}$ is the volatility of interest rates, and the increment $d z_{r}$ is a Wiener process. The house price $(H)$ is assumed to follow a Geometric Brownian Motion:

$$
\frac{d H}{H}=(\alpha-s) d t+\sigma_{H} d z_{H}
$$

where $d z_{H}$ is a Wiener process, $\alpha$ is the expected total return of the house, $s$ is the service flow provided by the house, and $\sigma_{H}$ is the volatility of the house price growth 
rate. The correlation between $d z_{r}$ and $d z_{H}$ is $\rho$. To employ the risk-neutral valuation, we use $r$, the risk-free rate, instead of the $\alpha$ in the equation in order to behave as though the world were risk-neutral. For a financial instrument whose price $f$ is contingent upon the underlying state variables expressed by equations (1) and (2), the second-order partial differential equation is:

$$
\begin{aligned}
& \frac{\partial f}{\partial t}+(r-s) H \frac{\partial f}{\partial H}+\gamma(\Theta-r) \frac{\partial f}{\partial r}+\frac{1}{2} H^{2} \sigma_{H}^{2} \frac{\partial^{2} f}{\partial H^{2}} \\
& \quad+\frac{1}{2} r \sigma_{r}^{2} \frac{\partial^{2} f}{\partial r^{2}}+\rho H \sqrt{r} \sigma_{H} \sigma_{r} \frac{\partial^{2} f}{\partial H \partial r}=r f .
\end{aligned}
$$

\section{Pricing model for servicing contracts without a delinquency decision}

Specifying the underlying boundary conditions is imperative for any contingent claim model. Mortgage borrowers have three possible options: prepayment, default (foreclosure), or making a regular payment to extend the options to the next period. However, a borrower first enters into delinquency if any payments are missed instead of directly going into foreclosure. Prior to the execution of the foreclosure process, the borrower has the right to cure the delinquency by bringing the mortgage payment current. To study rigorously this additional option, we evaluate the MSR with and without incorporating this particular delinquency option. That is, in addition to using the boundary conditions outlined in the traditional mortgage-pricing model, we also utilize the boundary conditions demonstrated in the work by Ambrose and Buttimer (2000). ${ }^{3}$

To establish the framework of the valuation problem, we begin by using a case that skips the delinquency stage. Keep in mind that the borrower seeks to minimize the value of his debt, which will result in the smallest value of the mortgage, based on the competitive prepayment, default, or continuation decisions. Following the work of Hilliard et al. (1998), the value of the mortgage is $V=U P B$ if prepayment; $V=H$ if default; and $V=A-C-D$ if continuation. ${ }^{4}$ Where $V$ stands for the value of the mortgage, $U P B$ is the unpaid principal balance, $H$ is the house price, $A$ represents the market value of the remaining payments as the mortgage is default free and without prepayments, $C$ represents prepayment option value, and $D$ represents default option value.

To summarize, from the borrower's perspective, the lender receives the unpaid principal balance if the borrowers prepay the loan. Similarly, if the borrowers default, the lenders receive the house. Finally, if the borrowers pay scheduled payment on time, the lender's position is the market value of the remaining payments less the value of the options to prepay and default in the future. In other words, the borrower's decision is to minimize the value of the mortgage given those three scenarios. At the last payment date (maturity date), the borrower will only pay the scheduled payment if the value of the house exceeds the unpaid principal balance; thus, the value of the mortgage is:

$$
V=\min \left(U P B_{T}, H_{T}\right)
$$

where default only occurs if the house price is less than the last payment. 
At the last payment due date, the value of the MSR can be computed as follows:

$$
\Pi_{T}=U P B_{T} \times\left(\frac{S F}{12}\right)-\left(\frac{S C}{12}\right)
$$

or

$$
\Pi_{T}=-\left(\frac{S C}{12}\right)-F C+R E_{T}
$$

where $\Pi_{T}$ is the value of the MSR cash flows at maturity and $U P B_{T}$ is the unpaid principal balance at maturity (i.e., at time $t=T$ ). $S F$ is the annual servicing fee, $S C$ is the annual servicing cost as a fixed dollar amount, $F C$ is the default (foreclosure) cost, and $R E_{T}$ will be the sum of previous missed servicing income plus the foreclosure cost. Equation (5) represents the value of the MSR if the borrower makes the final payment and equation (6) is the value of the MSR when the borrower defaults.

Mortgage default can only occur when the mortgage payment is due, thus the value of the mortgage immediately before a payment is due is:

$$
V=\min \left(U P B_{t}, H_{t}, A_{t}-C_{t}-D_{t}\right)
$$

Given that prepayment, default, and continuation are all possible, the value of the mortgage is computed using equation (7). If the borrower chooses to prepay, there will be no more future cash flows from servicing and thus servicing rights terminate. Therefore, the value of the MSR would be:

$$
\Pi_{t}=U P B_{t} \times\left(\frac{S F}{12}\right)-\left(\frac{S C}{12}\right)
$$

If instead, the borrower defaults, the value of the MSR would be:

$$
\Pi_{t}=-\left(\frac{S C}{12}\right)-F C+R E_{t}
$$

where $R E_{t}$ will be the function of previous missed servicing income plus the foreclosure cost. Finally, if the borrower makes the scheduled payment, the value of the MSR is the value of the MSR immediately after the regular payment is made $P V_{t}\left(\Pi_{t+1}\right)$ plus the cash flow received this period, less the servicing cost this period. Formally:

$$
\Pi_{t}=P V_{t}\left(\Pi_{t+1}\right)+U P B_{t} \times\left(\frac{S F}{12}\right)-\left(\frac{S C}{12}\right)
$$


Immediately before all nodes in the lattice where no monthly payment is due, the borrower's decision is either prepayment or continuation; thus, the mortgage value is:

$$
\begin{array}{r}
V=\min \left(U P B_{t}, A_{t}-C_{t}-D_{t}\right) . \\
\Pi_{t}=U P B_{t-1} \times\left(\frac{S F}{12}\right) \times\left(\frac{x}{30}\right)-\left(\frac{S C}{12}\right)
\end{array}
$$

where $x$ means that the prepayment occurs on the $x$ th day of the month. ${ }^{5}$

or

$$
\Pi_{t}=P V_{t}\left(\Pi_{t+1}\right)
$$

Mortgage prepayment is possible at any node in the lattice. Equation (12) represents the partial servicing income earned and servicing expenses incurred during the monthly interval. If the borrower is continuing to make the mortgage payment, the value of the MSR is essentially the present value of the MSR $P V_{t}\left(\Pi_{t+1}\right)$ at the subsequent nodes ahead in time.

\section{Pricing model for servicing contracts with a delinquency decision}

Prior to entering delinquency, the borrower has three options: prepayment, default (delinquency), or continuation. If the borrower chooses delinquency, three options remain during the delinquency period: foreclosure, reinstatement, or prepayment. Using equations (4) through (13), the value of the MSR can be determined using backward induction through the lattice until time $t=0$.

The key issue is how to compute the value of the servicing contract when entering delinquency. We initially evaluate the value of the MSR beyond the delinquency nodes at any point in time and then use backward induction to solve for the value at the node where delinquency occurs. Then we work backwards through time until $t=0$ (the origination point).

To illustrate the servicing valuation framework with a delinquency decision, we start with the discussion of the delinquency process. When the borrower enters delinquency, we assume that default (foreclosure) occurs with certainty three months after the delinquency date unless the borrower cures the mortgage from delinquency or prepays the loan by selling or refinancing the property. Therefore, at each delinquency node in the lattice, a 3-month lattice is added to test if any of the new boundary conditions are met. From this, we can determine if the borrower would choose to prepay, reinstate, or allow foreclosure. ${ }^{6}$ Therefore, the value of a MSR can be evaluated using on the following equations.

During the 3-month delinquency period, at the last payment date (maturity date), the value of the mortgage is: ${ }^{7}$

$$
V=\min \left(U P B_{S}+A R_{S}, H_{S}+d_{S}+c_{S}\right)
$$


where default only occurs if the sum of the house price $(H)$, the dollar amount of a deficiency judgment $(d)$, and the credit costs $(c)$ are less than the sum of the unpaid principal balance (UPB) and any arrears $(A R)$. With the delinquency decision embedded, the borrowers treat the value of the mortgage as the sum of the house price, a deficiency judgment, and credit costs when foreclosure occurs. We assume that all borrowers place a value on their credit rating, which is a constant percent of the outstanding mortgage amount. The additional items captured by $(A R)$ include the sum of all missed payments with the accrued interest and penalties on those missed payments.

At the last payment due date, the value of the MSR can be computed as follows:

$$
\Pi_{S}=U P B_{S} \times\left(\frac{S F}{12}\right)-\left(\frac{S C}{12}\right)+A R_{S}
$$

or

$$
\Pi_{S}=-\left(\frac{S C}{12}\right)-F C+R E_{S}
$$

If the borrower decides to make the final payment, the value of the MSR is given by equation (15). Equation (16) represents the value of the MSR when the borrower exercises the foreclosure option. The foreclosure option can only be exercised at the last payment node after delinquency and the term $R E_{S}$ will be the sum of three previous months of missed servicing income plus the foreclosure cost.

At the other two payment due dates during the delinquency period, the borrower has the right to stay until the third month. Therefore, at the payment due date, the value of the mortgage is:

$$
V=\min \left(U P B_{s}+A R_{s}, H_{s}+d_{s}+c_{s}, A_{s}-C_{s}-F R_{s}\right) .
$$

Given that prepayment, delinquency, and reinstatement are all possible, the value of the mortgage is expressed by equation (17). The $(F R)$ term represents the value of foreclosure option. If the mortgage is delinquent and the borrower keeps the foreclosure option that can be exercised at the third payment due date, the value of the MSR is:

$$
\Pi_{s}=P V_{s}\left(\Pi_{s+1}\right)
$$

If the borrower chooses to prepay, the value of the MSR is computed by equation (15) plus the amount of $A R$. Finally, if the borrower cures the mortgage from delinquency, the value of the MSR is:

$$
\Pi_{s}=\Pi_{s}^{+}+U P B_{s} \times\left(\frac{S F}{12}\right)-\left(\frac{S C}{12}\right)+A R_{s} .
$$

Equation (19) represents the value of the MSR if the borrower reinstates the loan when positive equity exists. ${ }^{8}$ Particular attention should be paid to the term $\Pi_{s}^{+}$that expresses the value of the MSR immediately after the loan is cured. That is, the MSR value consists of the sum of the present value of future MSR cash flows, the servicing income, and 
the amount of $A R$ from which the servicing costs in this period must be subtracted. One caveat is that the fact that the behavior of a cured mortgage is different from that of a loan that never entered into delinquency. In this paper, we make that simplifying assumption that our model ignores the path-dependence nature in the mortgage industry.

Immediately before all other payment nodes in the lattice where no payment is due,

$$
\begin{aligned}
V & =\min \left(U P B_{s}+A R_{s}, A_{s}-C_{s}-F R_{s}\right) \\
\Pi_{s} & =U P B_{s-1} \times\left(\frac{S F}{12}\right) \times\left(\frac{x}{30}\right)-\left(\frac{S C}{12}\right)+A R_{s} \\
\Pi_{s} & =\Pi_{s}^{+}+U P B_{s-1} \times\left(\frac{\mathrm{SF}}{12}\right) \times\left(\frac{x}{30}\right)-\left(\frac{S C}{12}\right)+A R_{s} \\
\Pi_{s} & =-D C+P V_{s}\left(\Pi_{s+1}\right)
\end{aligned}
$$

where $D C$ is the dollar cost to the servicer associated with the delinquency.

If prepayment occurs at a particular node during the delinquency month interval, equation (21) is used to compute the value of the MSR at that node. If reinstatement occurs, the value of the MSR can be derived using equation (22). Equation (23) shows that the value of the MSR at any delinquent node is the value of the MSR discounted back from all possible scenarios during the 3-month delinquency period with a deduction of delinquency costs at that particular node. ${ }^{9}$

\section{Results}

The base-case parameter values of the mortgage contract and economic environment shown in Table 1 are commonly used in mortgage pricing literature (e.g., Cox, Ingersoll and Ross, 1985; Kau et al., 1994; Hilliard et al., 1998; Ambrose and Buttimer, 2000). Therefore, we use these values so that our results can be directly compared to extant research.

Because the parameter values shown in table 1 are similar to previous literature, we include Table 2 to present the value of the mortgage under the base case in order to provide evidence supporting the reliability of our model.

\section{Interest-rate volatility}

Ceteris paribus, as interest-rate volatility increases the probability of future mortgage prepayment increases because of refinancing incentives. The change in potential prepayment has a significant effect on MSR valuation because servicing revenue is a function of unpaid principal balance. As shown in Table 3, an increase in interest-rate volatility leads to a decrease in the value of the MSR. That is, during periods of high interestrate volatility, the probability of prepayment increases, thereby decreasing the value of servicing rights. Thus, mortgage servicers should attempt to assess the likelihood of mortgage prepayment under various environments of interest-rate volatility. 
Table 1. Base-case parameters for numerical modeling

\begin{tabular}{ll}
\hline Parameters & Value \\
\hline & The Mortgage Servicing Contract \\
Contract rates $(C)$ & $9 \%$ \\
Loan-to-Value Ratio (LTV) & $90 \%$ \\
Original house values $\left(\mathrm{H}_{0}\right)$ & $\mathrm{US} \$ 200,000$ \\
Mortgage term & 30 years \\
Loan Type & Fixed-rate mortgage \\
Servicing income $(\mathrm{SF})$ & 0.0025 (Fannie/Freddie investor) \\
Annual servicing cost per loan $(\mathrm{SC})$ & $\$ 44$ (Fannie/Freddie investor) \\
Delinquency cost per loan & $\$ 265$ (Fannie/Freddie investor) \\
Foreclosure cost per loan & $\$ 2,000$ (Fannie/Freddie investor) \\
Foreclosure time allowed & $3 \mathrm{Months}$ \\
Credit cost & $1 \%$ \\
Default penalty & $0 \%$ \\
Deficiency judgment & $0 \%$ \\
& \\
Long-term mean $($ Steady-state spot rate) $(\theta)$ & $10 \%$ \\
Interest rate volatility $\left(\sigma_{r}\right)$ & $5 \%, 10 \%, 15 \%$ \\
Housing-price volatility $\left(\sigma_{H}\right)$ & $5 \%, 10 \%, 15 \%$ \\
Reversion coefficient $(\gamma)$ & $25 \%$ \\
House service flow $(\mathrm{s})$ & $8.5 \%$ \\
Original spot rate $\left(\mathrm{r}_{0}\right)$ & $8 \%$ \\
Correlation coefficient $\left(\rho_{r, H}\right)$ & $0 \%$ \\
\hline
\end{tabular}

*Data is from Citimortgage, Inc. For Fannie Mae / Freddie Mac investors, the cost of servicing is $\$ 44$ per loan annually and the servicing fee is 25 basis points per loan annually. In addition, the delinquency cost is $\$ 265$ and the foreclosure cost is $\$ 2,000$ if necessary.

Table 2. Mortgage values under various economic conditions assuming a 90\% LTV, a default period of 3 months, and a $1 \%$ credit cost associated with default (with and without a deficiency decision included)

\begin{tabular}{|c|c|c|c|c|c|c|c|}
\hline \multirow[b]{2}{*}{ MSR } & & \multicolumn{3}{|c|}{ Delinquency (without) } & \multicolumn{3}{|c|}{ Delinquency (with) } \\
\hline & & $\sigma_{r}=0.05$ & $\sigma_{r}=0.10$ & $\sigma_{r}=0.15$ & $\sigma_{r}=0.05$ & $\sigma_{r}=0.10$ & $\sigma_{r}=0.15$ \\
\hline \multirow[t]{3}{*}{$\gamma=0.25$} & $\sigma_{h}=0.05$ & 174,510 & 169,534 & 164,495 & 174,717 & 173,126 & 172,039 \\
\hline & $\sigma_{h}=0.10$ & 169,161 & 162,927 & 156,188 & 173,479 & 172,896 & 171,572 \\
\hline & $\sigma_{h}=0.15$ & 162,666 & 156,277 & 149,099 & 171,275 & 170,598 & 171,194 \\
\hline \multirow[t]{3}{*}{$\gamma=0.50$} & $\sigma_{h}=0.05$ & 171,511 & 170,756 & 170,360 & 170,946 & 171,897 & 171,956 \\
\hline & $\sigma_{h}=0.10$ & 167,645 & 166,786 & 164,415 & 167,457 & 169,838 & 171,458 \\
\hline & $\sigma_{h}=0.15$ & 161,948 & 160,813 & 158,156 & 161,956 & 166,498 & 170,136 \\
\hline \multirow[t]{3}{*}{$\gamma=0.75$} & $\sigma_{h}=0.05$ & 169,444 & 170,374 & 171,011 & 169,012 & 169,843 & 170,934 \\
\hline & $\sigma_{h}=0.10$ & 166,181 & 166,410 & 166,107 & 166,005 & 166,319 & 168,142 \\
\hline & $\sigma_{h}=0.15$ & 160,771 & 160,780 & 160,302 & 160,666 & 161,055 & 164,312 \\
\hline
\end{tabular}

Note: The analysis conducted is based on the following assumptions: the type of loan is a fixed-rate mortgage, the mortgage term is 30 years, there are two time steps per month, the initial market rate is $8 \%$, the contract rate is $8.5 \%$, the speed of adjustment factor is $25 \%$, the long-term mean reversion factor is $10 \%$, the house service flow is $8.5 \%$, the deficiency judgment is $0 \%$, the delinquency penalty is $0 \%$, the delinquency cost is $\$ 265$, the foreclosure cost is $\$ 2,000$, the servicing fee is 25 basis points, and the servicing costs is $\$ 44$ per loan. 
Table 3. Mortgage servicing values under various economic conditions assuming a $90 \%$ LTV, a default period of 3 months, and a $1 \%$ credit cost associated with default (with and without a deficiency decision included)

\begin{tabular}{|c|c|c|c|c|c|c|c|}
\hline \multirow[b]{2}{*}{ MSR } & & \multicolumn{3}{|c|}{ Delinquency (without) } & \multicolumn{3}{|c|}{ Delinquency (with) } \\
\hline & & $\sigma_{r}=0.05$ & $\sigma_{r}=0.10$ & $\sigma_{r}=0.15$ & $\sigma_{r}=0.05$ & $\sigma_{r}=0.10$ & $\sigma_{r}=0.15$ \\
\hline \multirow[t]{3}{*}{$\gamma=0.25$} & $\sigma_{h}=0.05$ & $2,401.79$ & $2,082.41$ & $1,800.99$ & $2,543.59$ & $2,181.65$ & $1,876.99$ \\
\hline & $\sigma_{h}=0.10$ & $1,674.25$ & $1,592.83$ & $1,459.06$ & $1,825.65$ & $1,703.21$ & $1,564.88$ \\
\hline & $\sigma_{h}=0.15$ & $1,456.37$ & $1,417.78$ & $1,355.94$ & $1,406.74$ & $1,367.28$ & $1,298.91$ \\
\hline \multirow[t]{3}{*}{$\gamma=0.50$} & $\sigma_{h}=0.05$ & $2,814.52$ & $2,494.68$ & $2,025.03$ & $3,184.58$ & $2,881.33$ & $2,289.86$ \\
\hline & $\sigma_{h}=0.10$ & $1,956.93$ & $1,860.83$ & $1,670.01$ & $2,256.11$ & $2,152,98$ & $1,994.32$ \\
\hline & $\sigma_{h}=0.15$ & $1,867.24$ & $1,648.17$ & $1,557.50$ & $1,823.34$ & $1,602.88$ & $1,509.27$ \\
\hline \multirow[t]{3}{*}{$\gamma=0.75$} & $\sigma_{h}=0.05$ & $3,130.46$ & $2,968.09$ & $2,428.06$ & $3,268.29$ & 3.088 .13 & $2,547.92$ \\
\hline & $\sigma_{h}=0.10$ & $2,364.90$ & $2,184.56$ & $1,846.82$ & $2,449.58$ & $2,241.89$ & $2,053.56$ \\
\hline & $\sigma_{h}=0.15$ & $2,097.37$ & $1,560.08$ & $1,385.33$ & $2,029.08$ & $1,487.63$ & $1,327.61$ \\
\hline
\end{tabular}

Note: The analysis conducted is based on the following assumptions: the type of loan is a fixed-rate mortgage, the mortgage term is 30 years, the initial market rate is $8 \%$, the contract rate is $8.5 \%$, the speed of adjustment factor is $25 \%$, the long-term mean reversion factor is $10 \%$, the house service flow is $8.5 \%$, the deficiency judgment is $0 \%$, the delinquency penalty is $0 \%$, the delinquency cost is $\$ 265$, the foreclosure cost is $\$ 2,000$, the servicing fee is 25 basis points, and the servicing costs is $\$ 44$ per loan.

\section{Housing-price volatility}

Table 3 also demonstrates the impact of changing housing-price volatility on the value of the MSR. Ceteris paribus, an increase in housing-price volatility leads to an increase in both default (foreclosure) and delinquency probabilities; therefore, the value of the MSR decreases during periods of high housing-price volatility.

Interestingly, during periods of high housing-price volatility, the value of the MSR without the delinquency option embedded is higher than that for the MSR with an embedded delinquency decision. Two factors may drive this. First, in our mortgage pricing models where default is synonymous with foreclosure the probability of delinquency is underestimated, which effectively reduces default costs. Secondly, with the delinquency option embedded, mortgage servicers incur both the delinquency costs and the foreclosure costs. Both costs lead to an increase in the servicing expenses when the mortgage goes into foreclosure process.

The value of the MSR with a delinquency option is higher than the value of the MSR without a delinquency option during periods of low housing-price volatility. This is because the costs incurred from the delinquent borrower have little impact on the servicing value during periods with relatively stable housing prices. With low housingprice volatility, the incidence of the delinquency is low; therefore, the benefits stemming from reinstatement outweigh the costs incurred from delinquency and foreclosure.

\section{Speed of adjustment}

The adjustment factor, $\gamma$, governs the speed of interest rate drift and thus its impact on the value of the MSR. The greater the speed of adjustment (the larger the adjustment factor), the faster interest rates will revert toward their long-term mean level. Table 3 


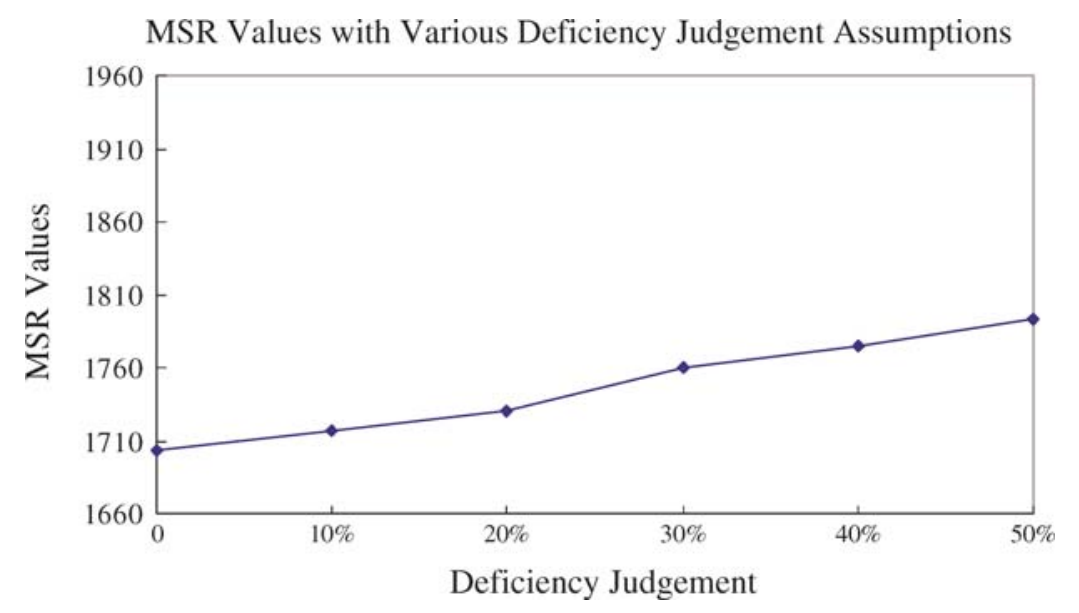

Figure 1. Mortgage Servicing Values Given Various Delinquency Judgment Assumptions.

shows that the value of the MSR changes significantly with various speeds of adjustment. This suggests that the prepayment effect on the MSR value appears to be insignificant when the speed of the adjustment becomes large.

\section{Deficiency judgments}

In the U.S., many states use deficiency judgments to control default behavior. These deficiency judgments allow the servicer (lender) to recover any deficiencies from the borrower's other assets. For the base case $\left(\sigma_{H}=\sigma_{r}=10\right.$ percent), figure 1 shows the impact of increasing the probability of obtaining a deficiency judgment from $0 \%$ to $50 \%$, ceteris paribus. The result is that the value of the MSR increases with an increase in the probability of obtaining a deficiency judgment. This occurs because the probability of delinquency decreases dramatically as the probability of a deficiency judgment increases; thus, the corresponding costs associated with delinquency and foreclosure are reduced.

\section{Default penalties}

Our model assumes that the borrower must fully cure the mortgage from delinquency by paying all arrears and penalties. Taking the base case where $\sigma_{H}=\sigma_{r}=10$ percent, figure 2 shows that the value of the MSR increases when we increase the delinquency penalty imposed from $0 \%$ to the maximum $11.5 \% .{ }^{10}$ This result indicates that imposing a penalty associated with delinquency reduces the likelihood of delinquency, thereby increasing the value of servicing. Notice that this only works for a pure "willingness to pay" problem. However, in reality it may have the opposite effect on the MSR value caused by "ability to pay" defaults. 


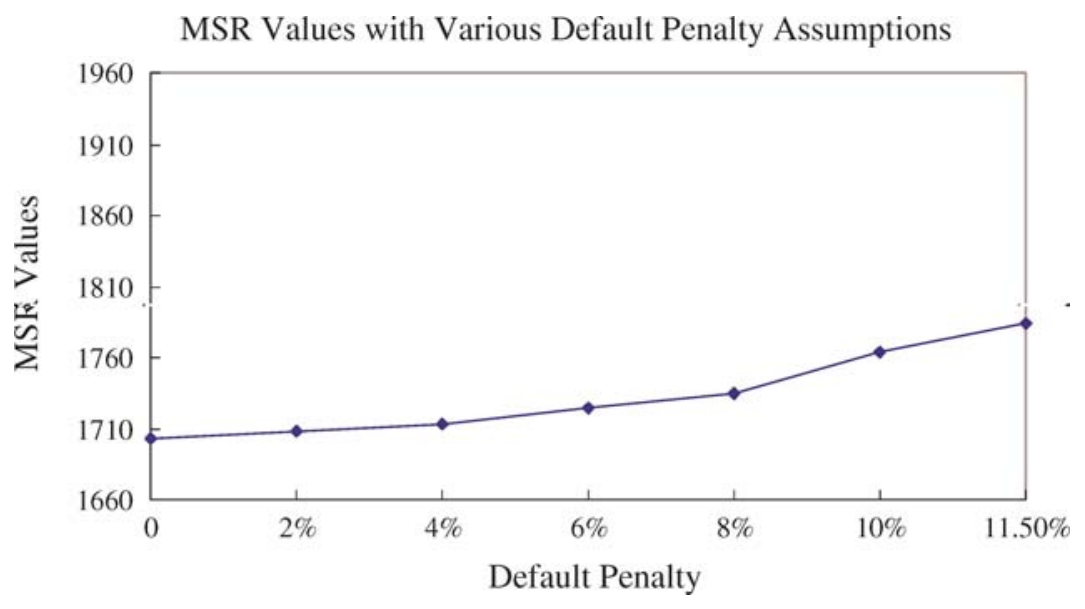

Figure 2. Mortgage Servicing Values Given Various Default Penalty Assumptions.

MSR Values with Various Foreclosure Delay Assumptions

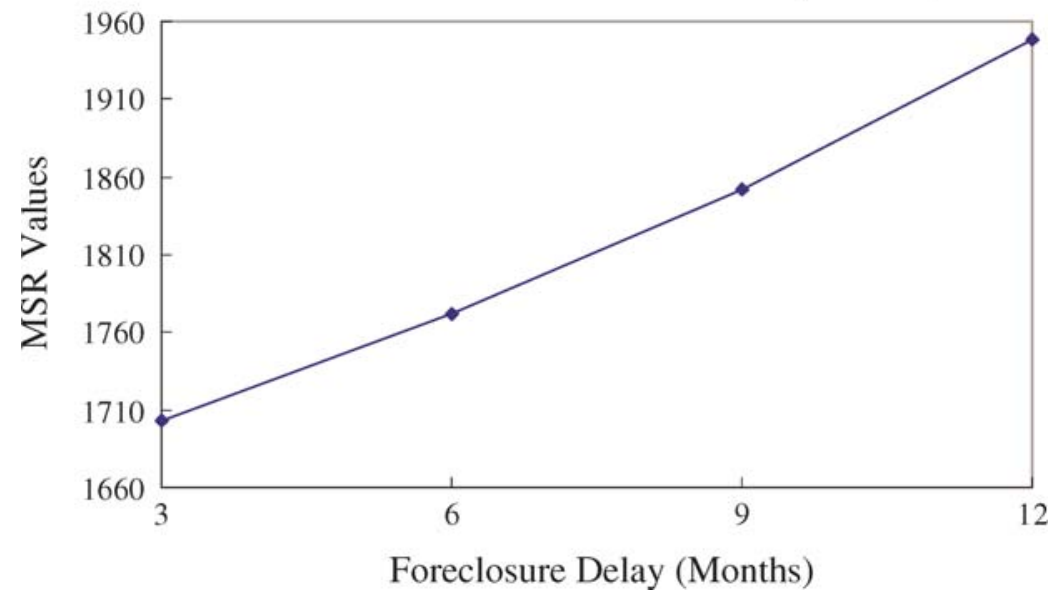

Figure 3. Mortgage Servicing Values Given Various Foreclosure Delay Assumptions.

\section{Forbearance periods}

When foreclosure proceedings are initiated, the servicer has the ability to slow down the process in order to allow a borrower that is experiencing temporary financial difficulties to reinstate the mortgage. Taking the base case where $\sigma_{H}=\sigma_{r}=10$ percent, figure 3 indicates that the value of the MSR increases as the delay increases from 3 to 12 months. This result occurs because increasing the forbearance period delays the negative payment and provides higher probability that the borrowers will be able to cure the delinquent loans. Thus, allowing forbearance generates higher servicing income than 
the delinquency costs that are incurred. Therefore, a loss-mitigation program that allows a delay in foreclosure is beneficial to the mortgage servicer. However, in real life an increase in the forbearance periods could cause moral hazard problem in that borrowers become more likely to enter delinquency. Thus, the servicer would face additional costs associated with delinquency and the value of the MSR would decline. Therefore, the results could be reversed.

\section{Conclusion}

We develop a bivariate binomial model to price Mortgage Servicing Rights (MSRs). This model extends previous MSR pricing models by explicitly incorporating the assumptions that there are additional costs involved in servicing delinquent loans; thus, it establishes a valuation framework for MSRs with and without a delinquency decision mechanism embedded. By adding additional sub-branches to the Hilliard et al. mortgage-pricing tree, we can model the borrower's decision of prepayment, cure, and foreclosure after a loan becomes delinquent.

Using the model we develop, we then investigate how the value of the Mortgage Servicing Right varies with interest rate volatility, house price volatility, delinquency options, deficiency judgments, default penalties, forbearance periods, and speed of adjustments factors. Our numerical results show that both interest-rate volatility and housing-price volatility have considerable impacts on the value of servicing contracts. With loss-mitigation programs implemented, our results provide policy implications that are potentially useful for servicers to deal with delinquent borrowers that have the greatest likelihood of going into foreclosure. These programs include deficiency judgment, default penalty, and loan forbearance periods. By wisely utilizing these weapons in controlling the borrower's payment behavior, an increase in the value of the MSR can be achieved through raising the probability of obtaining a deficiency judgment, imposing a higher default penalty, extending loan forbearance periods.

\section{Notes}

1. See Angbazo et al. (1998).

2. See Hilliard et al. (1998) and Ambrose and Buttimer (2000).

3. Ambrose and Buttimer (2000) indicate that the option to reinstate the mortgage does not change the prepayment boundary conditions, while the default options do change the prepayment boundary conditions.

4. See Hilliard et al. (1998) for a derivation of the value of the mortgage.

5. For the purpose of simplicity, our model assumes only one node exists between two payment due dates. That is, the $x$ stands for the 15th day of the month.

6. During the delinquency period, we assume that only one delinquency is allowed even though the borrower reinstates the mortgage.

7. The amount in arrears includes interest accrued on missed payments and the delinquency penalty. Consistent with the study by Ambrose and Buttimer (2000), penalties typically are assumed to be a percentage of the unpaid principal balance.

8. Equation (19) suggests that the delinquent sub-branches are allowed to return to the main tree if the delinquent loan is cured.

9. The servicing cost is ignored in the delinquency node because we have taken into account those costs during the delinquency period.

10. Following Ambrose and Buttimer (2000), the delinquency penalty in this paper is set at $11.5 \%$. 


\section{References}

Aldrich, S. P. B., W. R. Greenberg and B. S. Payner, "A Capital Markets View of Mortgage Servicing Rights." Journal of Fixed Income 11, 37-54 (2000).

Angbazo, L. A., J. J. McConnell, I. F. Megbolugbe and T. T. Yang, "Mortgage Prepayment Float: Pricing and Risk Analysis." Journal of Fixed Income, 83-93 (1998).

Ambrose, B. W. and R. J. Buttimer, "Embedded Options in the Mortgage Contract." Journal of Real Estate Finance \& Economics 2, 95-111 (2000).

Brown, S., L., Hayre, K. Lauterbach, R. Payne and T. Zimmerman, "Analysis of Mortgage Servicing Portfolios." Journal of Fixed Income 2, 60-76 (1992).

Buttimer, R. J. and C. C. Lin, "Valuing U.S. and Canadian Mortgage Servicing Rights." Journal of Housing Economics, forthcoming (2005).

Cox, J. C., J. E. Ingersoll, Jr. and S. A., Ross, “A Theory of the Term Structure of Interest Rates.” Econometrica 53, 385-407 (1985).

Hilliard, J. E., J. B. Kau and V. C. Slawson, "Valuing Prepayment and Default in a Fixed-Rate Mortgage: A Bivariate Binomial Option Pricing Technique.” Real Estate Economics 26, 431-468 (1998).

Kau, J. B., D. C. Keenan, W. J. Muller III and J. F. Epperson, "The Value at Origination of Fixed-Rate Mortgages with Default and Prepayment.” Journal of Real Estate Finance and Economics 11, 5-36 (1994).

Lin, C. C. and L. C. Ho "Valuing Individual Mortgage Servicing Contracts: A Comparison between Fixed-Rate Mortgages and Adjustable-Rate Mortgages." Review of Pacific Basin and Financial Markets and Policies, forthcoming (2005).

McConnell, J. J., "Valuation of a Mortgage Company's Servicing Portfolio.” Journal of Financial and Quantitative Analysis 11, 433-53 (1976).

Van Drunen, L. D. and J. J. McConnell, "Valuing Mortgage Loan Servicing." Journal of Real Estate Finance and Economics 1, 5-22 (1988). 